\title{
A Fusion Context-Aware Model based on Hybrid Sensing for Recommendation Smart Service
}

\author{
Svetlana $\mathrm{Kim}^{\dagger} \cdot$ Yonglk Yoon ${ }^{++}$
}

\begin{abstract}
Variety of smart devices including smart phone have become and essential item in user's daily life. This means that smart devices are good mediators to get collecting user's behavior by sensors mounted on the devices. The information from smart devices is important clues to identify by analyzing the user's preferences and needs. Through this, the intelligent service which is fitted to the user is possible.

This paper propose a smart service recommendation model based on user scenario using fusion context-awareness. The information for recommendation services is collected to make the scenario depending on time, location, action based on the Fusion process. The scenarios can help predict a user's situation and provide the services in advance. Also, content categories as well as the content types are determined depending on the scenario. The scenario is a method for providing the best service as well as a basis for the user's situation. Using this method, proposing a smart service model with the fusion context-awareness based on the hybrid sensing is the goal of this paper.
\end{abstract}

Keywords : Context-Awareness Modeling, Smart Device, Fusion, Hybrid Sensing, Smart Service, Scenario

\section{지능형 스마트 서비스를 위한 하이브리드 센싱 기반의 퓨전 상황인지 모델 \\ 김 스베틀라나 + 윤 용 익 ${ }^{++}$}

\begin{abstract}
요 약
스마트폰을 비롯한 다양한 스마트 디바이스들은 이제 사용자의 일상에서 필수적인 아이템으로 자리 잡았다. 스마트 디바이스 내에 센서정보 를 이용하여 사용자의 선호도 및 필요정보를 파악할 수 있으며, 이를 통해 지능적인 서비스 추천이 가능해진다는 의미이다.

본 논문에서 사용자의 상황정보를 토대로 지능적인 서비스 추천을 위한 퓨전(Fusion) 상황인지 모델을 제안하고자 하다. 서비스 추천 모델 은 스마트 디바이스로부터 획득한 시간, 장소, 행동 및 디바이스 정보를 중심으로 퓨전 처리과정을 거쳐 사용자 시나리오를 생성된다. 시나리오 란 사용자의 상황을 예측하는데 가장 핵심이 되는 단서이며, 본 시나리오에 맞춰 서비스를 제공 및 추천할 수 있다. 이 뿐만 아니라, 콘텐츠의 카테고리와 더불어 콘텐츠 미디어 형식까지도 사용자 맞춤형을 지향한다. 그러므로 본 논문에서 제안하는 퓨전 상황인지 모델은 하이브리드 센 싱(Hybrid Sensing)을 이용하였다.
\end{abstract}

키워드 : 상황인지 모델, 스마트 디바이스, 퓨전, 하이브리드 센싱, 스마트 서비스, 시나리오

\section{1. 서 론}

스마트 디바이스로부터 얻어지는 사용자 상황정보는 지능 형 추천 서비스를 위해 필히 고려되어야 할 사항들이다. 성 공적인 스마트 서비스를 제공하기 위해서는 사용자가 흥미

본 연구는 숙명여자대학교 2012학년도 교내연구비 지원에 의해 수행되었음

† 준 회 원 : 숙명여자대학교 멀티미디어과학과 박사과정

† 종신회원 : 숙명여자대학교 멀티미디어과학과 교수

논문접수 : 2012년 8월 2일

수 정 일 : 1 차 2012년 11월 1일

심사완료 : 2012년 11월 9일

* Corresponding Author:YongIk Yoon(yiyoon@sm.ac.kr)
를 가질 수 있고, 필요로 하는 서비스 및 정보를 최대한 가 깝게 예측하고 제안하는 기능이 필요하기 때문이다. 이를 위해 다양한 센서를 통한 사용자의 행동정보를 분석 및 가 공하는 과정이 필수적이다.

서비스 제공자들은 이러한 사용자 상황정보를 활용하여 사용자들을 위한 맞춤형 리치서비스(rich service)를 제공할 수 있다. 현재는 사용자의 위치나 시간을 기반으로 한 컨텍 스트 맞춤형 서비스(context-aware service)는 많은 주목을 받고 있으며 꾸준히 연구 진행 중이다. 이는 스마트 디바이 스에 정착된 다양한 센서들로부터 획득되는 센싱정보를 이 
용할 수 있기에 가능해지는 일이다. 또한 스마트 디바이스 내에서 실행되는 다양한 애플리케이션 데이터들 역시 사용 자를 파악하기 위한 유용한 정보가 된다.

문제는 규칙성 없이 수집된 정보들은 오히려 사용자의 상 황을 파악하기에 어려움을 불러일으킬 수 있다. 따라서 사 용자로부터 획득할 수 있는 정보들 중 필요한 주요 정보를 정확하게 식별하여 서로 간 의미적 조합을 필수적으로 이루 어져야 한다. 의미적 조합을 통해 사용자가 어떤 위치에 어 떤 시간에 어떤 애플리케이션을 사용을 하는지에 대한 판단 과 서비스를 예측하는데 강력한 이점으로 작용할 수 있다. 이를 위해 각 정보들은 주요 카테고리로 정렬한 후 카테고 리 간 관계 정보를 체계적으로 표현할 수 있는 모델이 필요 하다.

이에 본 논문에서는 사용자의 상황정보 데이터를 수집을 하여 규칙적 사용자 패턴을 추출한 후 이를 기반으로 사용 자의 필요와 기호에 최대한 알맞은 서비스를 제공하기 위한 지능적 서비스 추천모델을 제시한다. 본 모델은 다양한 사 용자 상황정보를 획득하기 위해 하이브리드 센싱을 이용한 다. 하이브리드 센싱은 스마트 디바이스 외부로부터 얻어지 는 정보인 Physical sensing data 와 스마트 디바이스 내의 액션정보인 Virtual sensing data를 이용함을 의미한다. 획 득된 정보들은 필터링과 의미적 조합을 통한 퓨전 과정을 거치며 사용자의 지속적인 상황패턴이 예측되고 이후 제공 될 추천 시나리오를 판단하는 단서가 된다. 사용자의 행동 상황에 맞춰 다양한 종류의 서비스와 콘텐츠 형식은 시나리 오 기반으로 최적화되어, 사용자들은 내용적 형식적 만족감 을 얻을 수 있다고 예상한다.

\section{2. 관련 연구 및 필요성}

\section{1 상황정보 센싱 기반의 서비스 기법}

스마트 디바이스 플랫폼을 구축하기 위한 기반 기술로 제 일 주목 받고 있는 것이 상황인식(Context-Awareness) 기 술이다. 상황인식 기술은 사용자의 위치, 시간, 사용자의 행 동 및 작업 이력 등과 같은 사용자의 현재 상황정보 (Contextual information)를 파악하고 분석하여 사용자 현 상황에서 필요로 하는 서비스를 추출하여 구동시켜 주는 기 술이다. 이러한 상황정보는 센서 네트워크 내의 수많은 센 서로부터 수집된 자료들을 분석하여 파악될 수 있다. 실제 로 여러 분야에서 현재 이용되고 있는 위치기반 서비스도 상황인식 기술 중의 한 분야이다[1][2].

이동환경에서 위치정보는 가장 빈번하게 활용되고, 서비 스 제공을 위해 꼭 필요한 상황정보이다. 위치정보를 얻는 대표적인 방법에는 GPS(Global Positioning System)가 있 다. 2009년에 발표된 Service Oriented Architecture (SOA) 연구에서는 모바일 디바이스에 정착된 GPS 및 블루투스를 이용하여 사용자의 일정과 스케줄에 따른 콘텐츠 수집 및 처리 방식 연구를 진행되고 있다[2].

Udine 대학의 SMDC 연구소에서 개발한 Context-Aware
Browser $(\mathrm{CAB})$ 는 센싱을 통해 얻은 상황정보 바탕으로 적 절한 웹 콘텐츠를 검색하여 사용자에게 제공하는 서비스이 다[4]. 하지만 $\mathrm{CAB}$ 은 단순히 사용자의 위치를 판단하는 기 술이다[3].

SenSay는 Carnegie Mellon 대학교에서 연구한 Context-Aware Mobile Phone 연구는 마이크로폰 센서를 통하여 가속도 및 온도 데이터를 입력 받아 사용자의 상태 를 인지하였다[4]. 이 연구에서 사용자의 상태를 4 단계로 구분하여 상태 변화에 따른 수신모드를 변경을 실행하였다. 하지만 SenSay 획득된 각 정보를 사용자의 위치 정보들만 의 관계성을 체계적으로 표현하지 않아 실질적으로 상황인 지를 통한 서비스를 제공하기에는 부족함이 많았다.

이처럼 현재 진행되고 있는 연구에서는 시간 및 장소에만 국한된 상황인지 기술이기 때문에 실질적으로 사용자의 생 활 패턴 및 상황을 적극적으로 반영하기 어려운 실정이다 [5][6]. 또한 상황정보를 파악하고 서비스를 제공한다고 하더 라도 규칙성 없이 정보를 수집만으로 지능적으로 사용자의 편의를 고려한 서비스의 형태까지는 아직 많은 연구와 보완 이 필요하다.

\section{2 연구의 필요성}

센싱 기술을 포함한 모바일 단말기의 발달과 확산으로 미 래의 지식통신 서비스는 실시간으로 사용자의 행위를 포함 한 상황인식 정보들을 분석 및 판단하여 사용자 맞춤형 서 비스를 제공하는 기술이 요구되고 있다. 이를 위하여 사용 자의 위치, 상태, 행위 정보의 지능적인 분석을 통한 최적의 서비스를 사용자가 필요한 정확한 시점에 전달되도록 지원 하는 서비스 플랫폼 기술이 요구되고 있다. 실시간으로 사 용자의 행위를 포함한 상황인식 정보들을 분석 및 판단하여 사용자 맞춤형 서비스를 제공하는 기술이 요구되며, 수집된 상황 정보를 지능적으로 추론하는 기술이 함께 요구된다. 즉, 사용자에게 최적인 맞춤형 서비스를 제공하기 위하여 사용자의 상황정보의 인식 기술, 규칙적 사용자 패턴의 추 출 기술과 유무선 통합 환경에서 협업 대상에게 서비스를 정확하게 전달하는 기술이 필요하다.

\section{3. 하이브리드 센싱}

\section{1 전체 시스템 구성도}

본 장에서는 사용자 패턴에 맞는 지능적 서비스 추천모델 을 제공하기 위하여 Fig. 1과 같이 전체 시스템 구성도를 보여준다.

Fig. 1의 하이브리드 센싱 기반의 퓨전 상황인식 모델이 본 논문에서 추구하고 있는 지능형 서비스 추천 모델이다. 하이브리드 센싱은 두 가지 감지 단계를 - 물리적 센싱 (Physical Sensing), 가상 센싱(Virtual Sensing) - 통해 사 용자에 대한 상황정보를 수집한다.

물리적 센싱은 사용자의 위치, 시간, 단말의 $\mathrm{MAC}$ 주소, 성능, 소프트웨어 인터페이스 $(\mathrm{S} / \mathrm{W}-\mathrm{I})$ 의 상태 및 소프트웨어 


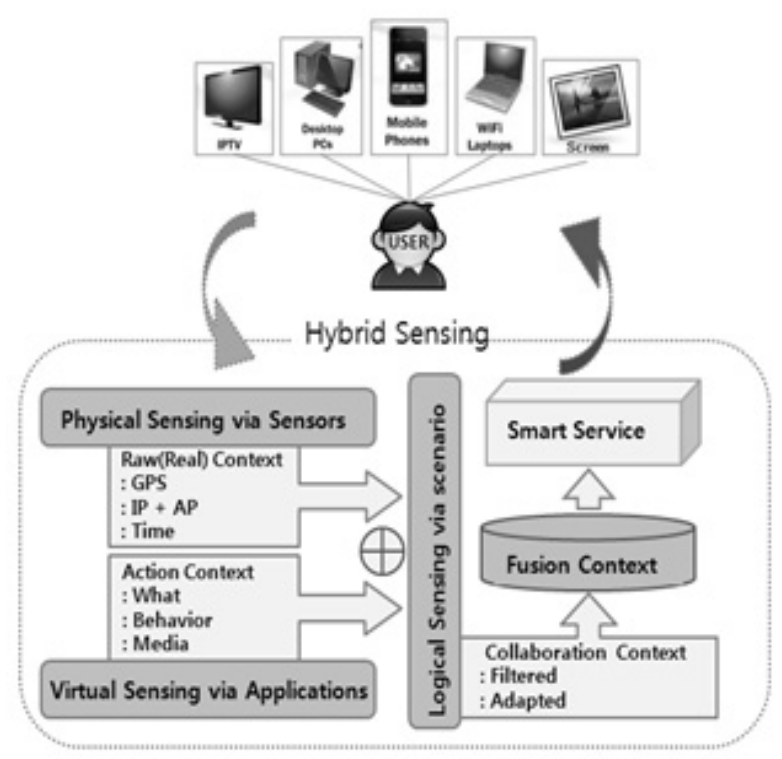

Fig. 1. Hybrid sensing architecture

응용프로그램의 $(\mathrm{S} / \mathrm{W}-\mathrm{A})$ 유형을 포함한다. $\mathrm{S} / \mathrm{W}-\mathrm{I}$ 는 프로세 스 속도, 메모리, 화면 크기, 해상도 및 단말기의 인터페이스 유형을 말한다. S/W-A 유형은 단말기에 설치된 혹은 사용 된 응용프로그램의 응답시간, 지연 및 $\mathrm{QOS}$ 의 매개 변수의 품질에 기반을 둔다.

가상 센싱은 디바이스의 내장된 시스템(센서)을 통해 사 용자의 상세 정보들을 수집할 수 있다. 스마트 디바이스는 인터넷에 접속이 되어 있으며, 이를 통해 다양한 응용프로 그램들을 디바이스에 설치 및 실행할 수 있다는 장점을 갖
고 있다. 이 특징은 사용자의 즉각적인 행동 및 사용자의 환경 설정을 식별하기에 적합하다. 즉, 응용프로그램의 형식, 실행시간, 수행 수, 접속 사이트 등 정보를 획득 할 수 있다.

하이브리드 센싱으로 지속적인 관찰을 통해 얻어진 정보 들은 논리적 센싱(Logical Sensing via Scenario)으로 전달 하게 된다. 논리적 센싱은 수집된 정보들을 식별하여 각 카 테고리에 분류한다. 카테고리가 형성이 된 후에는 시나리오 를 생성하기 위해 카테고리 간 의미적 조합이 이루어진다. 예를 들어, 사용자가 아침 9시로 모닝콜을 정해놓았을 경우 에도 오전 시간의 스케줄 정보 및 날씨, 교통정보 등을 활 용해 모닝콜이 울리는 시간을 추천해 줄 수 있도록 위치 정 보, 시간 정보 및 액션 정보(애플리케이션, 웹 데이터 등)들 을 결합하여 서로 비슷한 성향의 정보만을 조합한 후 퓨전 컨텍스트 데이터베이스에 복합정보로 저장한다.

퓨전 데이터베이스는 조합된 정보들의 특징과 패턴 관계 에 따라 융합되어 사용자에게 기호에 최대한 알맞은 시나리 오를 생성한다.

\section{2 논리적 센싱 구성도}

본 연구에서 제시된 전체시스템 구조에서 논리적 센싱은 가장 중요한 요소이며, 모든 상황정보들 간 관계성을 체계 적으로 표현할 수 있는 주요 단계이다(Fig. 2 참조).

논리적 센싱은 하이브리드 센싱으로부터 다양한 사용자의 상황정보들을 각 카테고리로 식별하여 서로 간 의미적인 조 합을 정의한다. Fig. 2와 같이 물리적 센싱정보와 가상 센싱 정보 바탕으로 $\mathrm{T}$ (time), $\mathrm{L}$ (location), $\mathrm{A}$ (action) 그리고 $\mathrm{D}$ (device) 카테고리로 식별한다.

물리적 센싱으로부터 얻어지는 현재의 $(\mathrm{L})$ 위치정보와 $(\mathrm{T})$

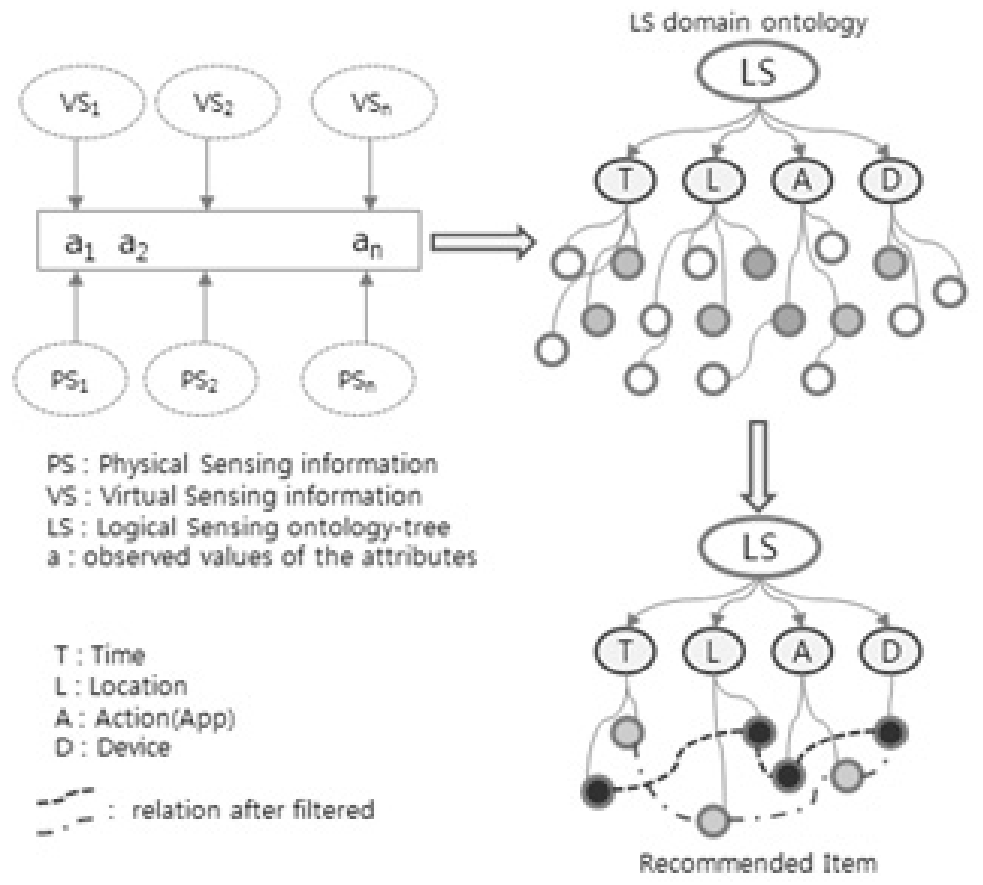

Fig. 2. Logical sensing diagram 
시간(스마트 디바이스에는 시간과 GPS 인식기가 장착되어 있음), (D)단말기의 IP주소와 $\mathrm{AP}($ Access Point), 다른 디바 이스와의 연결 유무와 같은 정보들로 분류한다. 가상 센싱 으로부터 얻어지는 $(\mathrm{A})$ 행동 혹은 애플리케이션, 접근 웹 사 이트, $\mathrm{SMS}$, 스케줄 정보들은 사용자가 요구하는 서비스의 종류뿐만 아니라 필요로 하는 기호와 선호를 결정할 수 있 는 단서가 된다.

식별된 카테고리에 각 정보의 관계를 표현하는 데에 필터 링 과정에서 평가(Rating) 기능을 사용한다. 평가 정의는 다 음과 같다:

$$
R: A \times T \times L \rightarrow \text { Rating }
$$

평가 기능은 $(\mathrm{A})$ 행동, $(\mathrm{T})$ 시간 그리고 $(\mathrm{L})$ 위치 정보를 포 함하는 카테고리를 결합하여 필터링한다. $\mathrm{R}(\mathrm{A}, \mathrm{T}, \mathrm{L})$ 은 사 용자가 어떤 장소 $\mathrm{L} \in$ Location에서 $\mathrm{T} \in \mathrm{Time}$ 해당 시간 에 주로 어떤 종류의 $\mathrm{A} \in \mathrm{Action}$ 애플리케이션(서비스)을 사용을 하는지에 대한 필터링 및 분리 작업을 거쳐 추출한 다. 여기서 $\mathrm{R}$ 은 각각의 $\mathrm{A}, \mathrm{T}, \mathrm{L}$ 을 평가하는 등급이다. 시각 적으로 필터링 처리과정의 등급 R은 Fig. 3에서 보이듯이 다차원 큐브에 저장하게 된다.

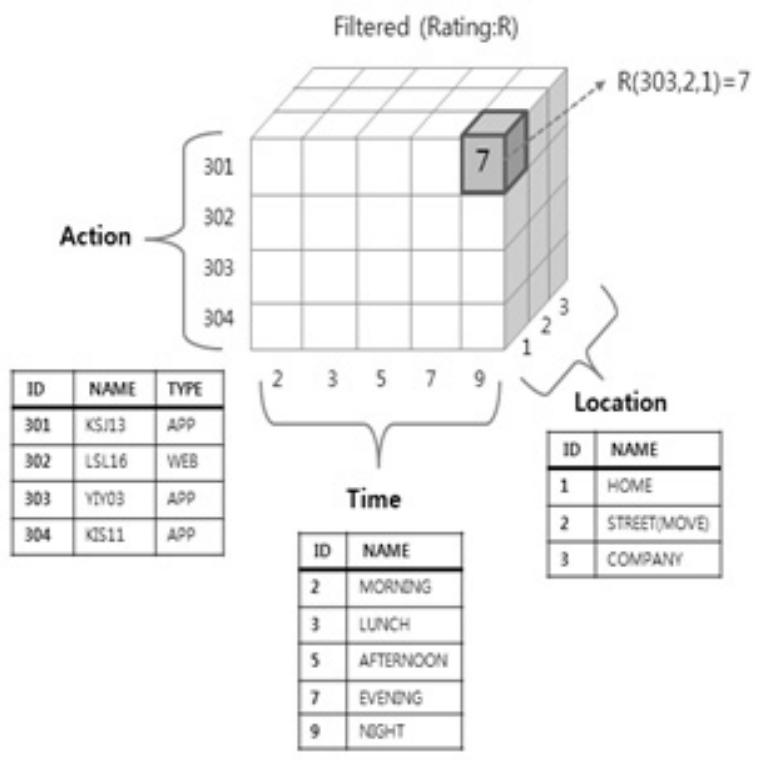

Fig. 3. $A \times T \times L$ - Filtering process

Fig. 3에서 큐브에는 주요 정보 카테고리를 해당 테이블 에 맞춰 결합한 후 $\mathrm{R}(\mathrm{A}, \mathrm{T}, \mathrm{L})$ 을 형성하여 저장한다. 예를 들어, 위 그림과 같이 $\mathrm{R}(303,2,1)=7$ 의 의미는 사용자가 아 침마다 집에서 YIY03응용프로그램을 실행하고 있다는 패턴 을 할 때, Action ID 가 303이며 Time ID 2이고 Location $\mathrm{ID}$ 는 1 로써 $\mathrm{R}$ 은 7 로 일정한 기간 동안 해당 서비스를 사용 하는 횟수를 의미하며 큐브 7에 해당하는 위치에 저장된다. 이렇게 필터링을 거쳐 결합된 정보는 스마트 서비스를 제공
하기 위한 시나리오를 생성하는데 기초가 된다. 필터링을 통한 평가정보에 따라 사용자의 행동 패턴을 확인 할 수 있 으며 이를 바탕으로 사용자가 어느 시간에 어느 장소에서 어떤 서비스를 필요로 하는지를 미리 예상할 수 있는 좋은 단서가 될 수 있는 것이다.

추천 시나리오는 사용자의 행동패턴 정보 바탕으로 이루 어지며 Table 1 과 같이 생성되어 Table 2와 같이 퓨전 데이 터베이스에 저장된다.

Table 1. Recommended scenario building

Building Recommended Scenario
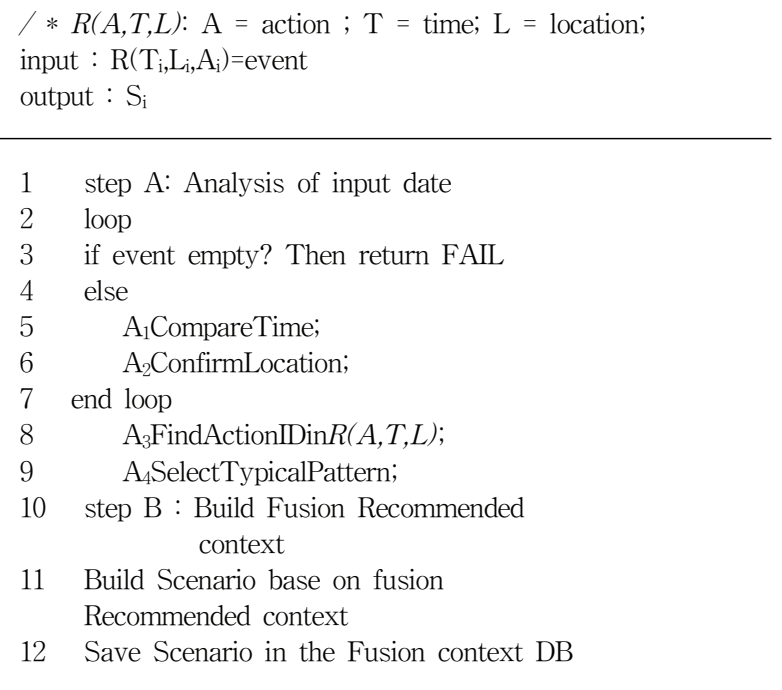

Table 2. Fusion-context Database

\begin{tabular}{llll}
\hline Time & Location & Action & Scenario \\
& & & \\
$\mathrm{T}_{1}=$ morning & $\mathrm{L}_{1}=$ home & $\mathrm{A}_{1}=$ web & $\mathrm{S}_{1}$ \\
$\mathrm{~T}_{2}=$ morning & $\mathrm{L}_{2}=$ street & $\mathrm{A}_{2}=$ app & $\mathrm{S}_{2}$ \\
$\mathrm{~T}_{3}=$ morning & $\mathrm{L}_{3}=$ company & $\mathrm{A}_{3}=$ app, & $\mathrm{S}_{3}$ \\
& & web & \\
\hline
\end{tabular}

퓨전 데이터베이스에 저장된 예제 시나리오는 매번 생성 되는 것이 아니라 일정한 기간 동안 수집되는 정보들 중에 가장 두드러지는 생활패턴을 대표한 것이다. 시나리오 $1\left(\mathrm{~S}_{1}\right)$ 은 사용자가 아침에 출근하기 전에 주로 사용하는 웹 서비 스를 보여주며 이를 기반으로 사용자가 선호하는 서비스를 미리 준비하여 대기상태로 화면에 표시하게 된다. 또한 위 치에 따라 콘텐츠 종류 선호도 및 기호, 디바이스 정보 등 시나리오에 맞춰 가장 대표적인 정보들만을 추가하여 제공 하게 된다. 이에 사용자가 직접 정보를 검색하고, 선택하고, 재생하는 번거로움을 없애기 위해 시나리오는 자동적이고 능동적으로 서비스를 추천하고 제공하는 것을 가능하게 할 것으로 예상된다. 
Table 3. The kind of content to according user's position

\begin{tabular}{|c|c|c|c|c|}
\hline Scenario & $\begin{array}{l}\text { Kind of } \\
\text { Content } \\
\text { (action) }\end{array}$ & Type & Device & $\begin{array}{l}\text { Connected } \\
\text { State }\end{array}$ \\
\hline $\mathrm{S}_{1}$ & $\begin{array}{c}\text { Schedule, } \\
\text { news, } \\
\text { weather info }\end{array}$ & Fusion & $\begin{array}{l}\text { Smart } \\
\text { phone }\end{array}$ & $\begin{array}{c}\text { TV, Tablet } \\
\text { PC } \\
\text { N-device }\end{array}$ \\
\hline $\mathrm{S}_{2}$ & $\begin{array}{l}\text { Schedule } \\
\text { traffic info }\end{array}$ & text & $\begin{array}{l}\text { Smart } \\
\text { phone }\end{array}$ & null \\
\hline $\mathrm{S}_{3}$ & $\begin{array}{l}\text { Schedule, } \\
\text { news }\end{array}$ & $\begin{array}{c}\text { Audio, } \\
\text { text }\end{array}$ & $\begin{array}{l}\text { Smart } \\
\text { phone }\end{array}$ & $\begin{array}{l}\text { Computer } \\
\text { Notebook }\end{array}$ \\
\hline
\end{tabular}

Table 3에서는 사용자의 위치에 따라 제공될 콘텐츠 서 비스를 예측하는 표이다. $\mathrm{S}_{1}$ 에서는 사용자의 위치는 집일 경 우 사용자가 주요 이용하는 서비스를 'fusion' 타입으로 제공 하는 것이다. Fusion 타입은 콘텐츠의 형태를 의미하고 있 으며 N-device에서 사용가능하도록 준비해 두는 것이다. 디 바이스의 사용가능한 여부는, 물리적 센싱으로부터 얻는 디 바이스(D) 정보에 의해 현재 사용자의 위치에서 연결 가능 한(Connected sate) 디바이스가 있는지 없는지 파악한 후 결정하게 된다. 예를 들어, 집에서 있는 디바이스들 중에 원 하는 디바이스를 선택하여 사용할 수 있도록 콘텐츠의 종류 를 여러 형태로 준비하여 바로 재생할 수 있는 상황을 말한 다. 만약에, 사용자가 즐겨보는 서비스가 '뉴스'이고 선택하 는 디바이스는 스마트 TV일 경우 뉴스를 영상 형태로 바로 $\mathrm{TV}$ 에 연결하여 재생 할 수 있다.

시나리오 $\mathrm{S}_{2}$ 에서는 사용자가 거리를 갖고 있는 상황을 말 한다. 본 시나리오 경우에는 거리에서 필요한 'traffic info'로 버스 도착 시간 혹은 도로상황 정보를 알려주며, 콘텐츠 타 입은 단순 텍스트로 제공하게 된다. 움직임이 있는 상황에 서는 영상 콘텐츠를 이용하기 힘들며 또한 위험할 수 있기 때문에 본 논문에서 특정한 장소에서만 영상 서비스가 제공 되도록 제한하였다.

본 논문에서 제안 된 추천 서비스 모델은 사용자의 필요 및 기호에 맞는 서비스를 제공뿐 아니라 안전 측면에서도 차별화된다고 생각한다. 또한 복합적인 사용자의 상황정보 를 의미 있는 조합을 하여 보다 정확하고 필요에 맞는 정보 들로 좁혀질 것으로 예상된다.

\section{4. 결 론}

본 논문에서는 사용자의 상황인지 정보를 바탕으로 필요 한 주요 정보로 정확하게 식별하여 서로 간 의미적 조합을 통한 규칙적 사용자 패턴을 추출하는 방법과 사용자 기호에 최대한 알맞은 서비스를 제공하기 위한 지능적 서비스 추천 방법을 제시하였다.
본 모델은 다양한 사용자 상황정보를 획득하기 위해 하이 브리드 센싱을 이용하여 사용자의 행동 상황에 맞춰 다양한 종류의 서비스와 콘텐츠 형식을 시나리오 기반으로 최적화 하였다.

상황인지 시나리오와 그에 따른 서비스 추천모델은 바쁜 일상 속에서 서비스를 보다 빠르게 편리하게 받아볼 수 있 으며 사용자에게 만족감을 줄 것으로 예상한다. 또한 사용 자들은 내용적 형식적 만족감을 얻을 수 있다고 예상한다.

상황인지 기술을 적극적으로 활용하여 사용자 파악에 있 어서 한결 수월하면서도 탁월한 시나리오를 생성함으로써 서비스를 제공하는 사업자 입장과 서비스를 이용하는 사용 자 입장을 모두 충족시키려고 한다.

향후 연구에서는 보다 세분화된 조건으로 시나리오를 형 성하려고 노력할 것이며 이를 바탕으로 한 구체적 서비스 방향에 대해 연구할 계획이다.

\section{참 고 문 헌}

[1] P. Zheng and L. M. Nio, "The rise of the smart phone," IEEE Distributed Systems Online, Vol.7, No.3, 2010.

[2] L. Yu and other, "Applying Context-awareness to Service-oriented Architecture," In Proceedings of IEEE International E-Business Engineering Conf. (ICEBE'09), pp.397-402, 2009.

[3] http://smdc.uniud.it/smdc/en/projects/cab

[4] Siewiorek,D.,A.Smailagic, J.Furukawa, N.Moraveji, K.Reiger, and J.Shaffer, "SenSay: A Context-Aware Mobile Phone," In Proc. of IEEE International Symposium on Wearable Comput ers (ISWC), 2003.

[5] M. Raento, A. Oulasvirta, R. Petit and H. Toivonen, "ContextPhone - A prototyping platform for context-aware mobile applications," IEEE Pervasive Computing, pp.51-59, 2005.

[6] P. Korpipaa, J. Mantyjarvi, J. Kela, H. Keranen, and E-J. Malm, "Managing context information in mobile devices," IEEE Pervasive Computing, Vol.2 Num. pp.42-51, ISSN 15361268, 3, 2003.

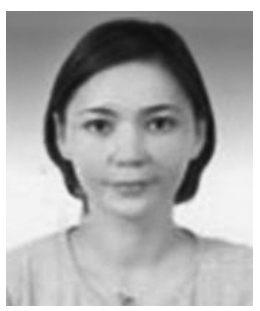

\section{김 스베틀라나}

e-mail:xatyna@nate.com 2004년 숙명여자대학교 멀티학과(이학사) 2007년 숙명여자대학교 멀티미디어과학과 (이학석사)

2007년 현 재 숙명여자대학교 멀티미디 어과학과 박사과정

관심분야: 유비쿼터스 컴퓨팅, 분산 미들웨어, 모바일 에이전트, MPEG-21, 실감 미디어, N-Screen 표준화, 모바일 클라우드 


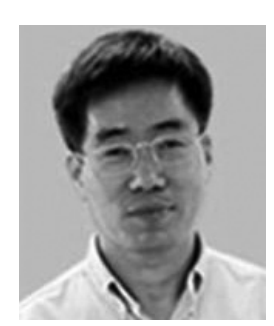

\section{윤 용 익}

e-mail : yiyoon@sm.ac.kr

1983년 동국대학교 통계학과(이학사)

1985년 한국과학기술원 전산학과

(공학석사)

1994년 한국과학기술원 전산학과 (공학박사)

1998년 현 재 숙명여자대학교 멀티미디어과학과 교수

관심분야: 유비쿼터스 컴퓨팅, 멀티미디어 시스템, 분산시스템,

실시간 처리시스템, 미들웨어, 실시간 $\mathrm{OS} / \mathrm{DBMS}$,

실감 미디어, N-Screen 표준화, 모바일 클라우드 